\title{
Superoxide Generation and Its Involvement in the Growth of Mycobacterium smegmatis
}

\author{
Amar M. Yeware ${ }^{\dagger}$, Ketaki D. Shurpalit, Meghana C. Athalye and Dhiman Sarkar* \\ Combi Chem-Bio Resource Center, Organic Chemistry Division, CSIR-National Chemical Laboratory, Pune, India
}

\section{OPEN ACCESS}

Edited by:

Martin Koenneke,

MARUM - Center for Marine Environmental Sciences, University of

Bremen, Germany

Reviewed by:

Diego Fabian Gomez-Casati, National University of Rosario (CONICET), Argentina

Paras Jain,

Albert Einstein College of Medicine,

USA

*Correspondence: Dhiman Sarkar d.sarkar@ncl.res.in

tThese authors have contributed equally to this work.

Specialty section:

This article was submitted to Microbial Physiology and Metabolism, a section of the journal

Frontiers in Microbiology

Received: 07 September 2016 Accepted: 13 January 2017 Published: 30 January 2017

Citation:

Yeware AM, Shurpali $K D$, Athalye MC and Sarkar D (2017)

Superoxide Generation and Its

Involvement in the Growth

of Mycobacterium smegmatis.

Front. Microbiol. 8:105.

doi: 10.3389/fmicb.2017.00105
Superoxide generation is inevitable in aerobic organisms, most of which have developed mechanisms to detoxify superoxides. However, its significance has not been clearly understood in mycobacteria. This study demonstrates that NADH oxidase is the major source of superoxide in Mycobacterium smegmatis and elucidates the involvement of superoxide in M. smegmatis growth. The maximum inhibition of superoxide generation was observed in the presence of diphenyleneiodonium chloride (DPI), an NADH oxidase inhibitor, compared to other standard inhibitors. After incubation for $24 \mathrm{~h}$, the number of colony forming units (CFUs) was reduced by $6.8 \log _{10}$ compared to the untreated culture. The inhibitory effect of DPI on $M$. smegmatis was reversed when the same culture was supplemented with menadione and pyrogallol, which are superoxide generators. Thus, this study reports the source of superoxide generation and its involvement in the growth of M. smegmatis.

Keywords: Reactive oxygen species, superoxide, diphenyleneiodonium chloride, Mycobacterium smegmatis, mycobacteria growth, NADH oxidase

\section{INTRODUCTION}

The survival of Mycobacterium tuberculosis (Mtb) the causative agent of tuberculosis inside the phagosomes of macrophages is critical for its virulence (Russell, 2001; Schnappinger et al., 2003; Rohde et al., 2007). Reactive oxygen species (ROS) and reactive nitrogen species (RNS) are secreted to kill the foreign bacteria inside macrophages (Chan et al., 1992; Adams et al., 1997; OberleyDeegan et al., 2010). Indeed, the influence of $\mathrm{O}_{2}$ on the growth of Mycobacterium spp. is wellknown (Wayne and Hayes, 1996; Kumar et al., 2008; Taneja et al., 2010). However, Mtb has evolved protective detoxification mechanisms in response to the exogenous oxidative stress encountered inside the host phagocytes.

ROS includes superoxide radicals, hydrogen peroxide, and hydroxyl radicals (Finkel, 2011). Mycobacterial antioxidant enzymes are known to play an important role in the defense against oxidative stress in macrophages; however, their expression in axenic cultures remains unclear. Mtb encounters ROS in the host and overcomes the oxidative stress through multiple thioredoxin systems that function as the antioxidant defense, such as thioredoxin reductase, thioredoxin C, and TPx (Jaeger et al., 2004). These findings also support that Mtb possesses a thiol-oxidoreductase system along with a superoxide-detoxifying enzyme (SodA) and an integral membrane protein (DoxX) called the membrane-associated oxidoreductase complex (MRC; Nambi et al., 2015). Paradoxically, earlier reports have suggested that a more oxidizing environment leads to the enhanced growth of M. abscessus as well as Mtb inside macrophages and a reducing environment inhibits their growth (Meylan et al., 1992; Oberley-Deegan et al., 2010). 
Although the role of ROS was earlier thought to be harmful, recent studies have highlighted them as significant physiological regulators of many cellular functions, such as transcriptional regulation, direct oxidative modification, protein turnover, protein-protein interaction, and enzyme modification (Figure 1) (Paulsen and Carroll, 2010; Finkel, 2011). ROSmediated signaling is controlled by a delicate balance between its formation and its scavenging (Bailey-Serres and Mittler, 2006). Further experimental evidences suggest the involvement of ROS in the growth of higher eukaryotes (Nathan and Shiloh, 2000; Bloomfield and Pears, 2003; Foreman et al., 2003; Saran, 2003; Finkel, 2011), lower eukaryotes (Buetler et al., 2004), yeast, as well as some prokaryotes (Diaz et al., 2013). Among ROS, superoxide is the first oxygen radical to be generated in cells.

Membrane-bound NADPH oxidase is the major source of superoxide in eukaryotic cells (Figure 1) (Paulsen and Carroll, 2010). However, in bacteria, NADH oxidase has been reported to produce superoxide, which is further converted to either $\mathrm{H}_{2} \mathrm{O}_{2}$ or $\mathrm{H}_{2} \mathrm{O}$ (Nishiyama et al., 2001; Yang and Ma, 2007; Diaz et al., 2013). Recent studies also suggest that Mtb generates endogenous superoxide, which is involved in the critical management of the redox balance. Moreover, the increasing level of endogenous superoxide differentially affects the growth of Mycobacterium spp. (Tyagi et al., 2015). Interestingly, there is no report on the involvement of superoxide in the growth of Mycobacterium spp. In this study, we demonstrate that $\mathrm{NADH}$ oxidase-derived superoxide is involved in the growth $M$. smegmatis.

\section{MATERIALS AND METHODS}

\section{Chemicals, Media, and Strain}

Dubos medium was purchased from DIFCO, USA and 2hydroxyethidium was purchased from Noxygen, Germany. All other chemicals were purchased from Sigma-Aldrich, USA.

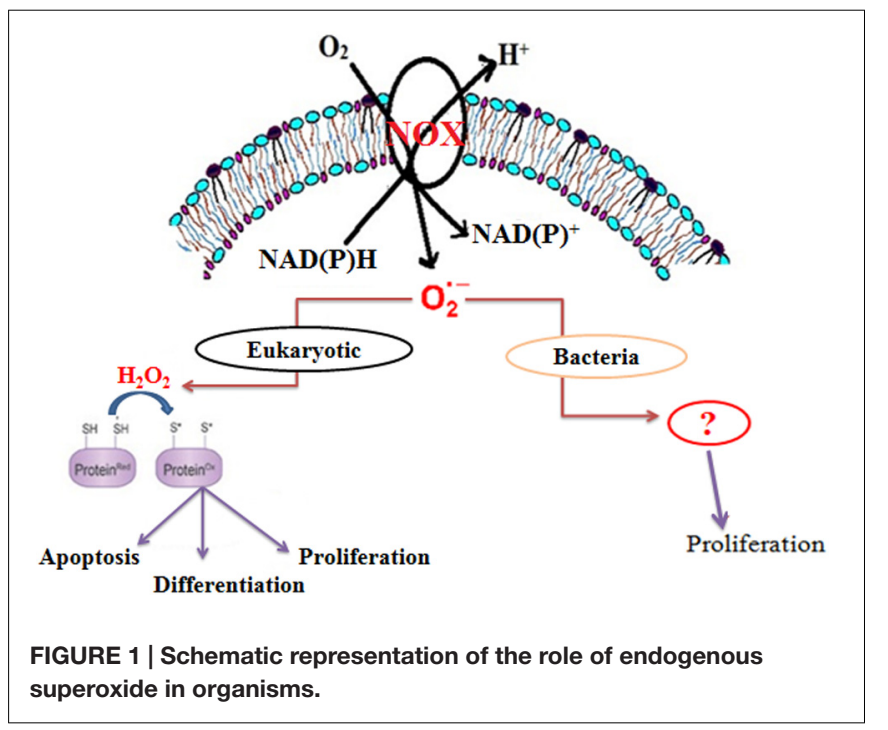

M. smegmatis $\mathrm{MC}^{2} 155$ strain was a gift from AstraZeneca, India. Sub-culturing of the strain was routinely performed on Dubos albumin agar slants. The stock was maintained at $-70^{\circ} \mathrm{C}$ and sub-cultured once in liquid medium before inoculation in the experimental culture medium. M. smegmatis culture was inoculated in $20 \mathrm{~mL}$ Dubos broth in a $100-\mathrm{mL}$ flask incubated at $37^{\circ} \mathrm{C}$ on an orbital shaker (Thermo Electron Model No.131 481; Thermo Electron Corp., Marietta, OH, USA) set at $150 \mathrm{rpm}$. Solutions of rotenone, antimycin A, DPI, menadione, pyrogallol, and dihydroxyethidum (DHE) were freshly prepared in dimethylsulfoxide (DMSO).

\section{Detection of Endogenous Superoxide Production in M. smegmatis}

Superoxide production in $M$. smegmatis was detected by the following modified HPLC-based method, described earlier (Laurindo et al., 2008; Zielonka et al., 2008, 2009). Briefly, $\sim 2.2 \times 10^{8}$ cells $/ \mathrm{mL}$ of aerobically growing $M$. smegmatis culture was washed and re-suspended in $1 \mathrm{~mL}$ of $M$. phlei medium (Khan et al., 2008) containing diethylenetriaminepentaacetic acid (DTPA) and incubated with DHE at a final concentration of $50 \mu \mathrm{M}$ at $37^{\circ} \mathrm{C}$ for $90 \mathrm{~min}$. After incubation, the cell pellet was obtained by centrifugation at $10,000 \mathrm{rpm}$ for $10 \mathrm{~min}$ at $4^{\circ} \mathrm{C}$, washed twice with $M$. phlei medium, and re-suspended in $500 \mu \mathrm{L}$ of the same medium containing $1-2 \%(\mathrm{v} / \mathrm{v})$ of Triton X100. After mixing, an equal volume of acidified methanol [with $1 \%$ formic acid (v/v)] was added and the cell suspension mix was kept on ice for $90 \mathrm{~min}$. The supernatant was collected after centrifugation at $15,000 \mathrm{rpm}$ for $45 \mathrm{~min}$ at $4^{\circ} \mathrm{C}$ and filtered through a $0.2-\mu \mathrm{m}$ membrane filter (Acrodisc $13 \mathrm{~mm}$ syringe filters, Pall Corporation). The filtrate was then analyzed using HPLC (Binary pump-1525, Fluorescence detector-2475, UV detector-2489, Sampler-2707, Waters, India). The chromatographic separation was performed on a C18 reverse phase column (Kinetex $5 \mu \mathrm{m} \mathrm{C18} \mathrm{100A,} 250 \mathrm{~mm} \times 4.60 \mathrm{~mm}$ from Phenomenex, India). A gradient of solutions A [1\% $(\mathrm{v} / \mathrm{v})$ formic acid in water] and B [1\% (v/v) formic acid in acetonitrile] was used as the mobile phase at a flow rate of $0.4 \mathrm{~mL} / \mathrm{min}$. Chromatographic runs were started with $100 \%$ solution A, decreased linearly to $60 \%$ solution A during the first $8 \mathrm{~min}$, and then kept constant at isocratic condition for a further $12 \mathrm{~min}$. In the next $1 \mathrm{~min}$, the gradient was set at $100 \%$ solution $\mathrm{B}$, kept constant for a further $4 \mathrm{~min}$, and equilibrated again with solution $\mathrm{A}$ for the next run. The 2hydroxyethidium fluorescence was monitored by a fluorescence detector (excitation $480 \mathrm{~nm}$, emission $580 \mathrm{~nm}$ ). The area under the curve of 2-hydroxyethidium and ethidium were considered and their concentrations were calculated based on a standard plot.

Superoxide production in the crude membrane was assessed by the method described above. Briefly, $15 \mu \mathrm{g}$ of the crude membrane protein was added to $500 \mu \mathrm{L}$ of $M$. phlei medium containing $100 \mu \mathrm{M}$ DTPA and $1 \mathrm{mM}$ NADH. Freshly prepared DHE was added at a final concentration of $25 \mu \mathrm{M}$ and the mix was incubated at $37^{\circ} \mathrm{C}$, following which HPLC samples were prepared as described earlier in this section. 
A

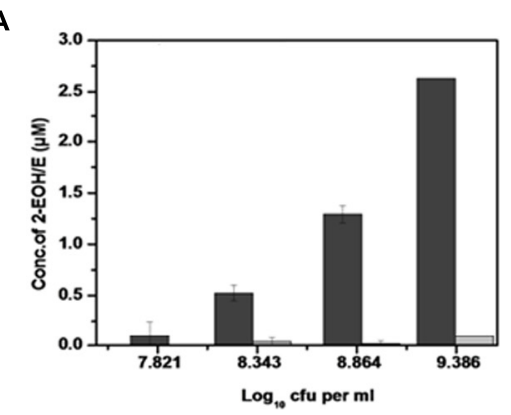

$\mathrm{Bi}$

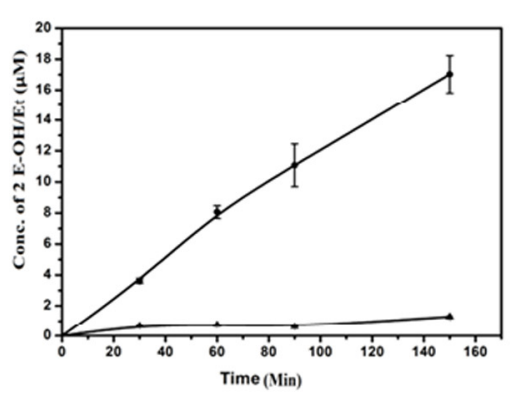

Bii

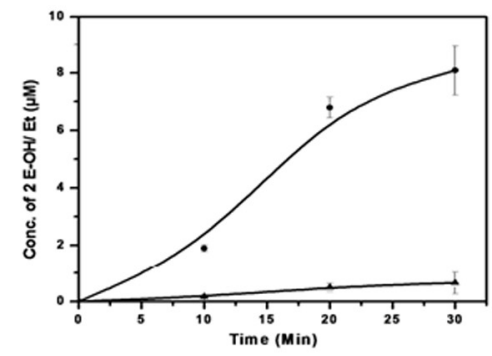

FIGURE 2 | Detection of superoxide produced by $\boldsymbol{M}$. smegmatis cells. (A) Cell concentration-dependent production of superoxide: Different concentrations of M. smegmatis cells were incubated with DHE for 90 min. After incubation, samples were further processed for HPLC analysis. Levels of 2-hydroxyethdium (2-EOH; dark bar) and ethidium (Et; gray bar) were determined from the standard plot.. The results represent the mean \pm SD of three identical experiments. ( $\rho<0.05$ ). (B) Time-dependent increase in superoxide production in (i) M. smegmatis and (ii) M. smegmatis membrane preparation: Approximately $2.2 \times 10^{8}$ cells/mL and $15 \mu \mathrm{g}$ of the membrane protein were distinctly incubated with DHE at different time points. Samples were further processed for HPLC analysis. Levels of 2 -EOH $(\bullet)$ and Et $(\boldsymbol{\Delta})$ were determined from the standard plot. The results represent the mean \pm SD of three identical experiments. $(p<0.05)$.

\section{Crude Membrane Preparation from M. smegmatis}

Crude membrane was prepared by a previously described method (Drew et al., 2006) with some modifications, as follows: $M$. smegmatis cells were harvested by centrifuging at $2,000 \times g$ for $15 \mathrm{~min}$ and re-suspended in $15 \mathrm{~mL}$ buffer containing $1 \mathrm{X}$ PBS ( $\mathrm{pH} 8.0$ ), $1 \mathrm{mg} / \mathrm{mL}$ EDTA, $0.002 \%$ lysozyme, and $1 \%$ protease inhibitor cocktail. The pellet was lysed by probe sonication (SONICS Vibra cell) of 10-s pulses for $20 \mathrm{~min}$. The lysate was then subjected to centrifugation at 5,000 rpm for $20 \mathrm{~min}$ at $4^{\circ} \mathrm{C}$

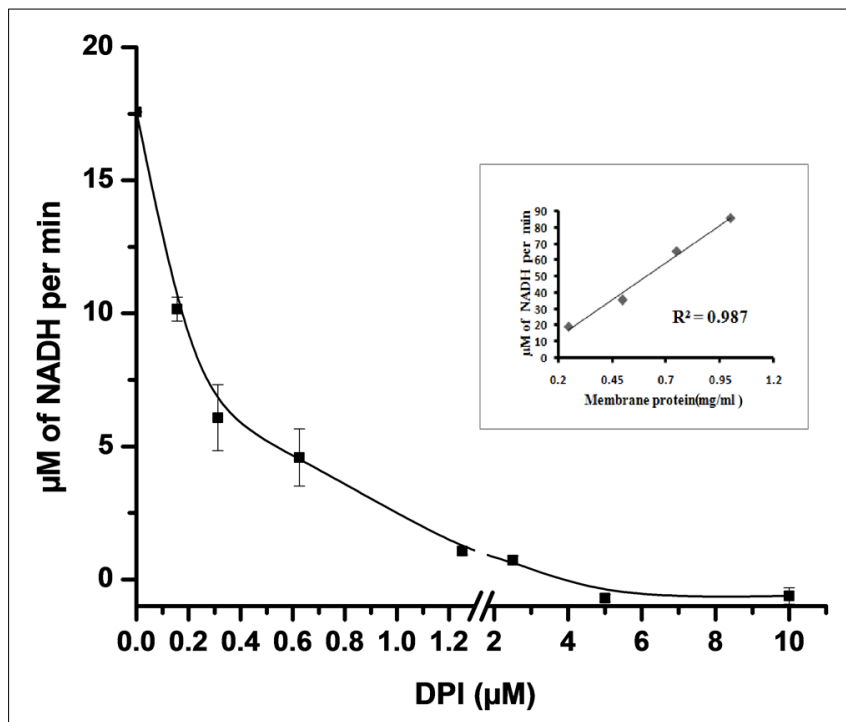

FIGURE 3 | Effect of DPI on NADH oxidase activity in crude membrane preparation. $50 \mu \mathrm{g}$ of crude membrane protein was incubated with different concentrations of DPI $(0.15-10 \mu \mathrm{M})$ in $50 \mathrm{mM}$ Tris buffer $(\mathrm{pH} 7.5)$ containing $500 \mu \mathrm{M}$ of $\mathrm{NADH}$ for $25 \mathrm{~min}$ at $30^{\circ} \mathrm{C}$. and inhibition activity determined measuring absorbance at $340 \mathrm{~nm}$. Inset: Plot showing crude membrane protein vs. NADH conversion per min $\left(R^{2}=0.987\right)$. The results represent the mean $\pm \mathrm{SD}$ of three identical experiments. to remove unbroken cells and cell debris. The supernatant was further subjected to ultracentrifugation at $120,000 \times g$ for $90 \mathrm{~min}$ at $4^{\circ} \mathrm{C}$ (Sorvall WX Ultra Series, Thermo Electron Corporation) and the pellet containing membrane proteins was obtained after washing with cold PBS. This membrane pellet was finally resuspended in $50 \mathrm{mM}$ Tris- $\mathrm{HCl}$ buffer at $\mathrm{pH} 8.0$

\section{Determination of NADH Oxidase Activity in Crude Membrane Preparation}

$\mathrm{NADH}$ oxidase activity was measured in the crude membrane of M. smegmatis according to an assay described earlier (Reusch and Burger, 1974) with some modifications, as follows: $50 \mu \mathrm{g}$ of membrane protein was added to $200 \mu \mathrm{L}$ of $50 \mathrm{mM}$ Tris buffer (pH 8) containing $100 \mu \mathrm{M}$ dithiothreitol and $500 \mu \mathrm{M} \mathrm{NADH}$ in a 96 -well quartz plate. The plate was incubated at $30^{\circ} \mathrm{C}$ with continuous shaking and the absorbance was monitored at $340 \mathrm{~nm}$ for 25 min (SpectraMax M5e Microplate Reader, Molecular Devices,USA). The inhibition of enzyme activity was determined by incubating various concentrations of DPI with above reaction mixture.

\section{Effect of ROS Modulators on the Growth of $M$. smegmatis}

The growth of $M$. smegmatis was determined in the presence of different ROS modulators by following a previously described protocol (Khan et al., 2008). Briefly, $0.1 \%$ of mid-log phase culture, at $\mathrm{OD}_{620}$ of 1.0 , was inoculated in $20 \mathrm{~mL}$ of Dubos medium at a final count of approximately $5.6 \times 10^{5}$ cells $/ \mathrm{mL}$ and incubated with different concentrations of ROS modulators for 4 days at $37^{\circ} \mathrm{C}$ with shaking at $120 \mathrm{rpm}$. M. smegmatis growth was estimated by determining the $\mathrm{CFU} / \mathrm{mL}$ after 3 days of incubation on Dubos agar plate.

The effect of menadione and pyrogallol on bacillus growth was determined in the presence of DPI $(15 \mu \mathrm{M})$. Mid-log phase cultures $\left(2.2 \times 10^{8}\right.$ cells $\left./ \mathrm{mL}\right)$ were supplemented with menadione $(150 \mu \mathrm{M})$ and pyrogallol $(300 \mu \mathrm{M})$ along with DPI and incubated 
A

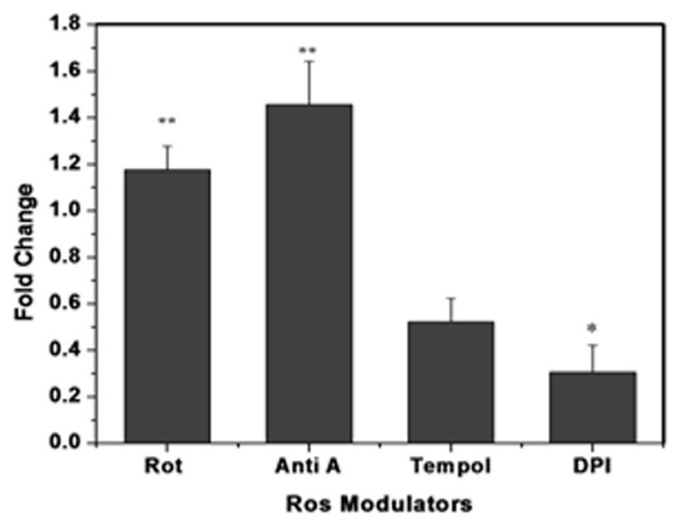

B

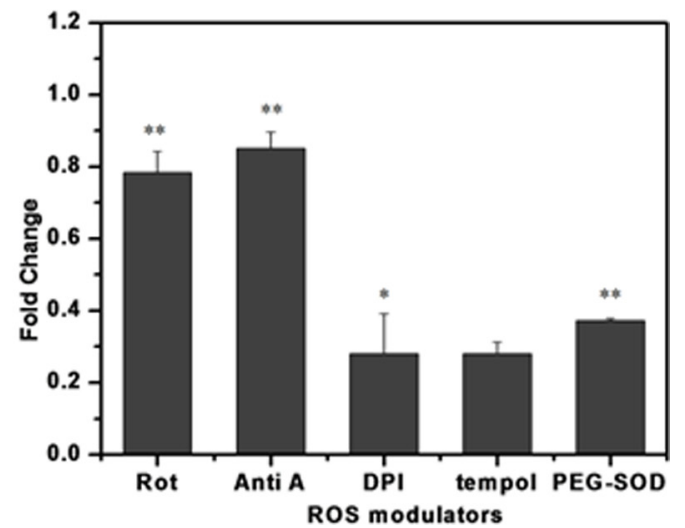

FIGURE 4 | Effect of different ROS modulators on superoxide production in $\boldsymbol{M}$. smegmatis. Rotenone (10 $\mu \mathrm{M})$, antimycin A (10 $\mu \mathrm{M})$, DPI (15 $\mu$ M), tempol $(10 \mu \mathrm{M})$, and PEG-SOD (5 units/mL) were incubated with (A) M. smegmatis and (B) membrane preparation. Samples were further processed for HPLC analysis. The results are expressed as fold change measured as the ratio of treated to untreated samples (control). The results represent the mean \pm SD of three identical experiments. $\left({ }^{*} p<0.05 ; * * p<0.1\right)$.

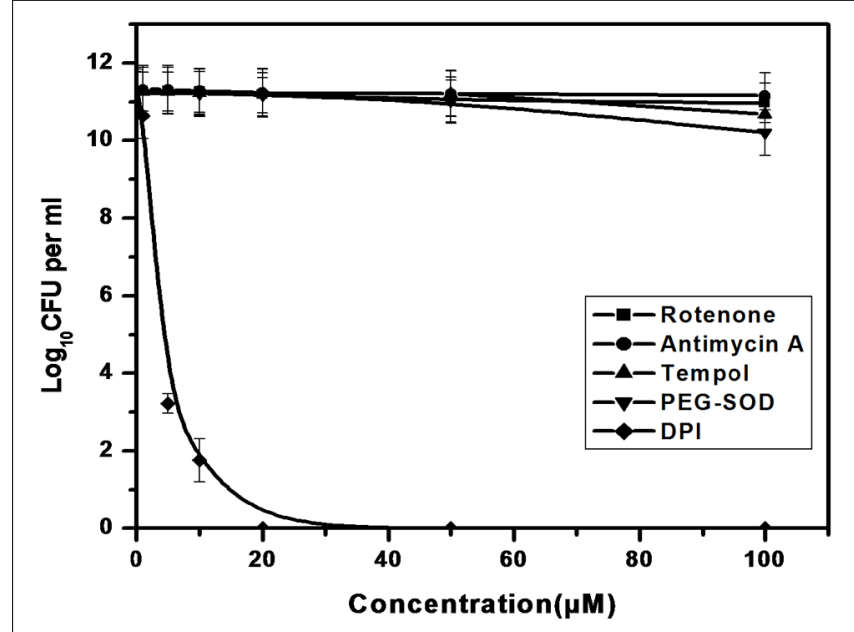

FIGURE 5 | Effect of ROS modulators on the growth of $\boldsymbol{M}$. smegmatis. Log phase culture of $M$. smegmatis consisting of $\sim 5.6 \times 10^{5}$ cells $/ \mathrm{mL}$ was grown in the presence of the ROS modulators for 4 days, following which the number of CFUs was calculated. Data shown are representative of four independent experiments.

for $24 \mathrm{~h}$. Measurements of CFU/mL were determined after 3 days of incubation at $37^{\circ} \mathrm{C}$ on Dubos agar plate.

\section{RESULTS}

\section{Detection of Superoxide Generation in Aerobically Growing M. smegmatis}

Superoxide is generated when one electron is added to an oxygen molecule and it plays an important role in the formation of other oxygen radicals (Turrens, 2003; Nicolopoulou-Stamati et al., 2004; Gülçin, 2006). Superoxide generation in M. smegmatis was measured using DHE (Figure 2 and Supplementary Figure 1).
DHE is a widely used probe that is oxidized by superoxide to yield fluorescent 2-hydroxyethidium and ethidium, both of which intercalate DNA and are efficiently retained by the cells (Fink et al., 2004; Laurindo et al., 2008; Zielonka et al., 2008, 2009). These two products, 2-hydroxyethidium and ethidium, were separated using HPLC at retention times of 18.6 and $19.2 \mathrm{~min}$, respectively (Supplementary Figure 2). We found an increase in the 2-hydroxyethidium fluorescence, which was proportional to the increase in cell number (Figure 2A). A continuous production of 2-hydroxyethidium led to its steady accumulation over a period of $150 \mathrm{~min}$ in whole cells and $30 \mathrm{~min}$ in membrane preparation (Figure $\mathbf{2 B}$ and Supplementary Figure 2). However, the low level of ethidium was not significantly affected in these experiments (White et al., 2014).

\section{Determination of NADH Oxidase Activity in Crude Membrane Preparation}

$\mathrm{NADH}$ oxidase generates superoxide by transferring electrons from $\mathrm{NADH}$ to molecular oxygen. $\mathrm{NADH}$ oxidase activity in crude membrane preparation was measured by the decrease in the absorbance of NADH at $340 \mathrm{~nm}$ for $25 \mathrm{~min}$. We observed that the rate of $\mathrm{NADH}$ utilization linearly increased with the increase in the total crude membrane protein concentration $\left(\mathrm{R}^{2}=0.987\right)$ in the reaction mixture (inset Figure 3$)$. The rate of NADH utilization was found to decrease with increasing DPI concentrations which indicates potential inhibition of $\mathrm{NADH}$ oxidase activity (Figure 3).

\section{Identification of the Source/s of Superoxide Generation in M. smegmatis}

To identify the possible source/s of superoxide generation in $M$. smegmatis cells, we tested the effects of various ROS modulators on $M$. smegmatis whole cells as well as on its crude membrane preparation and then monitored their effect on the oxidation 
of DHE to 2-hydroxyethidium (Figure 4) (Rottenberg et al., 2009). Tempol (4-hydroxy-Tempo) a cell permeable nitroxide of the superoxide dismutase (SOD) mimic class inhibited the production of 2-hydroxyethidium substantially by $0.52 \pm 0.084$ and $0.28 \pm 0.032$ fold in whole cells and in the membrane preparation, respectively, compared to the untreated control normalized value of 1 (Figures 4A,B) (Nandakumar et al., 2014) Polyethylene glycol-SOD (PEG-SOD) also inhibited 2hydroxyethidium production by $0.37 \pm 0.011$ fold in the crude membrane preparation compared to the untreated control. DPI reduced the maximum of 2-hydroxyethidium production by $0.30 \pm 0.093$ and $0.27 \pm 0.102$ fold in whole cells and in the membrane preparation, respectively. The electron transport chain (ETC) inhibitors, rotenone (complex I, NADH dehydrogenase) and antimycin A (complex III, cytochrome-bc1 complex), did not inhibit the production of 2-hydroxyethidium; instead, resulted in a $1.17 \pm 0.12$ and $1.45 \pm 0.12$ fold increase in 2-hydroxyethidium levels, respectively, in whole cells, as reported earlier (Verkaart et al., 2007; Piskernik et al., 2008). Similarly, in membrane preparations, rotenone and antimycin A inhibited 2-hydroxyethidium production only by $0.78 \pm 0.068$ and $0.85 \pm 0.046$ fold, respectively (Figure 4). Interestingly, M. smegmatis cells were viable after treatment with these ROS modulators for $90 \mathrm{~min}$, indicating that the observed fold changes in 2-hydroxyethidum were not due to cell death (data not shown).

\section{Effect of ROS Modulators on the Growth of $M$. smegmatis}

We further investigated the possible adverse effects of ROS modulators on $M$. smegmatis growth. ETC inhibitors (Rotenone and Antimycin A), tempol and PEG-SOD did not affect the CFU counts of $M$. smegmatis even 10-fold higher concentration used than the superoxide detection experiment (Figure 5). In contrast, only DPI inhibited the growth of $M$. smegmatis, possibly owing to the depletion of superoxide within the cell (Figure 5).

\section{Superoxide Involvement in $M$. smegmatis Growth}

To determine the involvement of superoxide in M. smegmatis growth, we added menadione and pyrogallol, separately and along with DPI, to the M. smegmatis culture and observed their effect on superoxide production as well as bacilli growth. Menadione $(150 \mu \mathrm{M})$ and pyrogallol $(300 \mu \mathrm{M})$ increased superoxide production by $1.41 \pm 0.062$ and $1.14 \pm 0.041$ fold, respectively, when added separately, and by $0.45 \pm 0.13$ to $1.12 \pm 0.101$ fold and $0.99 \pm 0.022$ fold, respectively, when added along with DPI (Figure 6A). DPI reduced the bacilli growth by a difference of $6.8 \log _{10}$ compared to the growth in the untreated control. This effect was reversed when menadione or pyrogallol was added, showing a difference of only 1.5 or $1.9 \log _{10}$, respectively, compared to the growth in the untreated control (Figure 6B). To optimize the concentration of menadione and pyrogallol, a prior dose response study was carried out in the presence of a fixed concentration of DPI (data not shown). Thus, this study establishes that DPI inhibits growth through the inhibition of superoxide production in M. smegmatis.

\section{DISCUSSION}

Earlier studies have demonstrated that the level of superoxide production is proportional to the availability of $\mathrm{O}_{2}$ in the environment (Bloomfield and Pears, 2003; Foreman et al., 2003; Buetler et al., 2004; Shi et al., 2008). Our initial studies using DHE have clearly established that actively growing $M$. smegmatis bacilli continuously produce superoxide radicals (Figure 2 ). The
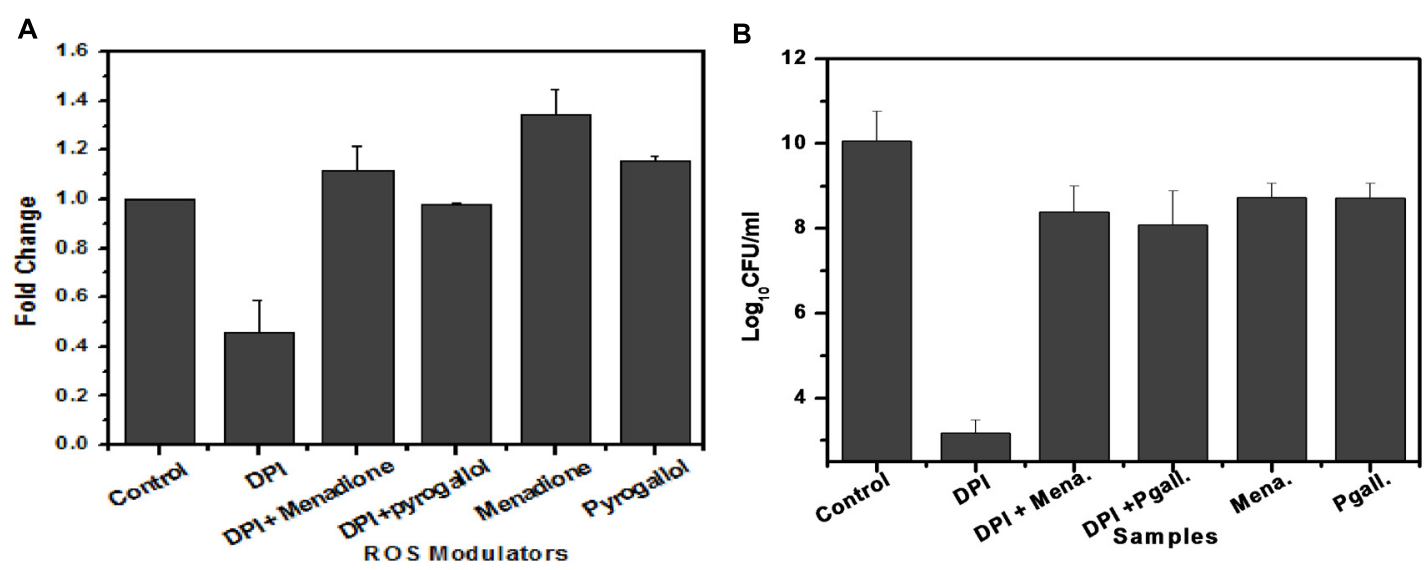

FIGURE 6 | Involvement of superoxide in the growth of $\boldsymbol{M}$. smegmatis. (A) Effect of ROS modulators and generators on superoxide production by $\mathbf{M}$. smegmatis. M. smegmatis cells were incubated with DPI $(15 \mu \mathrm{M})$, DPI (15 $\mu \mathrm{M})+$ menadione $(150 \mu \mathrm{M})$, DPI $(15 \mu \mathrm{M})+$ pyrogallol $(300 \mu \mathrm{M})$, menadione $(150 \mu \mathrm{M})$, and pyrogallol $(300 \mu \mathrm{M})$ for $90 \mathrm{~min}$. Samples were further processed as described in Figure 3 . The results represent the mean $\pm \mathrm{SD}$ of three identical experiments. ( $p$ < 0.05). (B) Effect of ROS modulators and generators on the growth of $M$. smegmatis. Log phase culture of $M$. smegmatis consisting of $\sim 2.3 \times 10^{8}$ cells $/ \mathrm{mL}$ was incubated with DPI $(15 \mu \mathrm{M})$, DPI $(15 \mu \mathrm{M})+$ menadione $(150 \mu \mathrm{M})$, DPI $(15 \mu \mathrm{M})+$ pyrogallol $(300 \mu \mathrm{M})$, menadione (150 $\mu \mathrm{M})$, and pyrogallol $(300 \mu \mathrm{M})$ for $24 \mathrm{~h}$, after which plating was done on Dubos agar plates. CFU measurements were performed after 3 days of incubation. Data shown are representative of three independent experiments. 
superoxide level needs a critical management by mycobacterial antioxidant enzymes to ensure its beneficial functioning in the bacilli. Thus, this justifies the expression of antioxidant enzymes in axenic cultures as reported earlier (Muller et al., 2004; Suresh et al., 2010).

Previous studies on different prokaryotic organisms have shown that $\mathrm{NADH}$ oxidase and menaquinone, associated with ETC, are the two major sites of superoxide generation in these organisms (Chandel et al., 2000; Zalba et al., 2000; Hasan et al., 2006). DPI inhibits NADPH oxidase in eukaryotes and has a homologous mechanism similar to $\mathrm{NADH}$ oxidase present in bacteria (Li and Trush, 1998; Korshunov and Imlay, 2006; Diaz et al., 2013). Additionally, inhibition of NADH oxidation by DPI in the crude membrane preparation confirms the presence of $\mathrm{NADH}$ oxidase-like enzyme in the membrane of $M$. smegmatis (Figure 3).

In accordance with earlier studies, our results clearly indicate that DPI significantly inhibits superoxide production in whole cells as well as in the membrane preparation of $M$. smegmatis (Figure 4) However, contribution of ETC in superoxide production remains unclear due to the lack of significant effect of any of the ETC inhibitors in M. smegmatis Thus, we identified $\mathrm{NADH}$ oxidase as the most probable source of superoxide production in M. smegmatis. Interestingly M. smegmatis possesses four isozymes of NADH oxidase (KEGG database). Further studies on these NADH oxidase isozymes will clarify their role in superoxide production.

In our study, DPI was found to decrease the superoxide generation as well as the growth of the $M$. smegmatis bacilli (Figure 6). Reversion of the effect of DPI on the bacilli growth by superoxide generators (menadione and pyrogallol) confirmed the involvement of superoxide in M. smegmatis growth (Figure 6B). Previous in vivo studies have shown similar inhibitory effects of plant-derived antioxidants against $M$. intracellulare as well as against $M$. abscessus (Reddy et al., 2007). As reported earlier, rotenone and antimycin A neither inhibited superoxide production (Verkaart et al., 2007; Piskernik et al., 2008) nor showed any effect on the bacilli growth (Figure 5) (Parrish et al., 2004; Megehee et al., 2006). PEG-SOD depleted superoxide in membrane preparations, but its inefficiency to inhibit the bacilli growth could be due to a poor penetration through the mycobacterial cell membrane, which could be attributed to its high molecular weight. In contrast to DPI, tempol did not inhibit superoxide production. Tempol has been reported to facilitate the dismutation of superoxide like SOD, to hydrogen peroxide and to exhibit a catalase-like activity (Wilcox and Pearlman, 2008). Therefore, the inability of tempol to inhibit growth, albeit with the reduction in the superoxide level, could be attributed to the possible involvement of other ROS. In the case of DPI, inhibition of the superoxide source could possibly lead to a significant

\section{REFERENCES}

Adams, L. B., Dinauer, M. C., Morgenstern, D. E., and Krahenbuhl, J. L. (1997). Comparison of the roles of reactive oxygen and nitrogen intermediates in the host response to Mycobacterium tuberculosis using transgenic mice. Tuber. Lung Dis. 78, 237-246. doi: 10.1016/S0962-8479(97)90004-6 decrease in the subsequent generation of other ROS. Under physiological conditions, the role of superoxide will remain important, as it is also the primary source of other oxygen radicals. Our results suggest that other ROS could be possibly associated with the growth of the cells. Further studies will be necessary to find out which ROS species is more closely involved in the regulation of mycobacterial growth.

The involvement of superoxide in the regulation of mycobacterial growth is a new finding and is in accordance with earlier reports on the involvement of superoxide in the growth regulation of some prokaryotes and eukaryotes (Bloomfield and Pears, 2003; Foreman et al., 2003; Buetler et al., 2004; Diaz et al., 2013). Thus, our study provides new insights into mycobacterial growth regulation during hypoxia and under vitamin C-induced dormancy as well (Wayne and Hayes, 1996; Taneja et al., 2010). In summary, this study demonstrates that a significant amount of superoxide is actively generated by M. smegmatis and that NADH oxidase is its major contributor. Our results also suggest that superoxide may play an important role in the growth regulation of the M. smegmatis bacilli.

\section{AUTHOR CONTRIBUTIONS}

This study was designed and done by all authors. AY and KS participated equally in all this work, whereas MA helped them with membrane preparation and related studies under the guidance of DS.

\section{FUNDING}

The Council of Scientific and Industrial Research, India provided the financial assistance for this work through the grant-in aid project (BSC0103).

\section{ACKNOWLEDGMENT}

We express our gratitude to AstraZeneca R\&D Bangalore, India for providing the M. smegmatis $\mathrm{mc}^{2} 155$ strain as a gift. AY, KS, and MA are thankful to DST-INSPIRE, CSIR and UGC for their fellowships respectively.

\section{SUPPLEMENTARY MATERIAL}

The Supplementary Material for this article can be found online at: http://journal.frontiersin.org/article/10.3389/fmicb. 2017.00105/full\#supplementary-material

Bailey-Serres, J., and Mittler, R. (2006). The roles of reactive oxygen species in plant cells. Plant Physiol. 141:311. doi: 10.1104/pp.104.90 0191

Bloomfield, G., and Pears, C. (2003). Superoxide signalling required for multicellular development of Dictyostelium. J. Cell Sci. 116, 3387-3397. doi: $10.1242 /$ jcs. 00649 
Buetler, T. M., Krauskopf, A., and Ruegg, U. T. (2004). Role of superoxide as a signaling molecule. News Physiol. Sci. 19, 120-123.

Chan, J., Xing, Y., Magliozzo, R. S., and Bloom, B. R. (1992). Killing of virulent Mycobacterium tuberculosis by reactive nitrogen intermediates produced by activated murine macrophages. J. Exp. Med. 175, 1111-1122. doi: 10.1084/jem. 175.4.1111

Chandel, N. S., McClintock, D. S., Feliciano, C. E., Wood, T. M., Melendez, J. A., and Rodriguez, A. M. (2000). Reactive oxygen species generated at mitochondrial complex III stabilize hypoxia-inducible factor-1( $\alpha$ during hypoxia. J. Biol. Chem. 275, 25130-25138. doi: 10.1074/jbc.M001914200

Diaz, J. M., Hansel, C. M., Voelker, B. M., Mendes, C. M., Andeer, P. F., and Zhang, T. (2013). Widespread production of extracellular superoxide by heterotrophic bacteria. Sci. 340, 1223-1226. doi: 10.1126/science.1237331

Drew, D., Lerch, M., Kunji, E., Slotboom, D. J., and de Gier, J. W. (2006). Optimization of membrane protein overexpression and purification using GFP fusions. Nat.Methods 3, 303-313. doi: 10.1038/nmeth0406-303

Fink, B., Laude, K., McCann, L., Doughan, A., Harrison, D. G., and Dikalov, S. (2004). Detection of intracellular superoxide formation in endothelial cells and intact tissues using dihydroethidium and an HPLC-based assay. Am. J. Physiol. Cell Physiol. 287, C895-C902. doi: 10.1152/ajpcell.00028.2004

Finkel, T. (2011). Signal transduction by reactive oxygen species. J. Cell. Biol. 194, 7-15. doi: 10.1083/jcb.201102095

Foreman, J., Demidchik, V., Bothwell, J. H., Mylona, P., Miedema, H., Torres, M. A., et al. (2003). Reactive oxygen species produced by NADPH oxidase regulates plant cell growth. Nature 422, 442-446. doi: 10.1038/nature01485

Gülçin, I. (2006). Antioxidant activity of caffeic acid (3, 4-dihydroxycinnamic acid). Toxicology 217, 213-220. doi: 10.1016/j.tox.2005.09.011

Hasan, N., Yusuf, N., Toossi, Z., and Islam, N. (2006). Suppression of Mycobacterium tuberculosis induced reactive oxygen species (ROS) and TNF- $(\alpha$ mRNA expression in human monocytes by allicin. FEBS Lett. 580, 2517-2522. doi: 10.1016/j.febslet.2006.03.071

Jaeger, T., Budde, H., Flohé, L., Menge, U., Singh, M., Trujillo, M., et al. (2004). Multiple thioredoxin-mediated routes to detoxify hydroperoxides in Mycobacterium tuberculosis. Arch. Biochem. Biophys. 423, 182-191. doi: 10. 1016/j.abb.2003.11.021

Khan, A., Akhtar, S., Ahmad, J. N., and Sarkar, D. (2008). Presence of a functional nitrate assimilation pathway in Mycobacterium smegmatis. Microb. Pathog. 44, 71-77. doi: 10.1016/j.micpath.2007.08.006

Korshunov, S., and Imlay, J. A. (2006). Detection and quantification of superoxide formed within the periplasm of Escherichia coli. J. Bacteriol. 188, 6326-6334. doi: 10.1128/JB.00554-06

Kumar, A., Deshane, J. S., Crossman, D. K., Bolisetty, S., Yan, B. S., Kramnik, I., et al. (2008). Heme Oxygenase-1-derived carbon monoxide induces the Mycobacterium tuberculosis dormancy regulon. J. Biol. Chem. 283, 1803218039. doi: 10.1074/jbc.M802274200

Laurindo, F. R. M., Fernandes, D. C., and Santos, C. X. C. (2008). Assessment of superoxide production and NADPH oxidase activity by HPLC analysis of dihydroethidium oxidation products. Methods Enzymol. 441, 237-260. doi: 10.1016/S0076-6879(08)01213-5

Li, Y., and Trush, M. A. (1998). Diphenyleneiodonium, an NAD(P)H oxidase inhibitor, also potently inhibits mitochondrial reactive oxygen species production. Biochem. Biophys. Res. Commun. 253, 295-299. doi: 10.1006/bbrc. 1998.9729

Megehee, J. A., Hosler, J. P., and Lundrigan, M. D. (2006). Evidence for a cytochrome bcc-aa3 interaction in the respiratory chain of Mycobacterium smegmatis. Microbiology 152, 823-829. doi: 10.1099/mic.0.28723-0

Meylan, P. R., Richman, D. D., and Kornbluth, R. S. (1992). Reduced intracellular growth of mycobacteria in human macrophages cultivated at physiologic oxygen pressure. Am. Rev. Respir. Dis. 145, 947-953. doi: 10.1164/ajrccm/145. $4 \backslash \_\mathrm{Pt} \backslash$ 1.947

Muller, F. L., Liu, Y., and Van Remmen, H. (2004). Complex III releases superoxide to both sides of the inner mitochondrial membrane. J. Biol. Chem. 279, 49064-49073. doi: 10.1074/jbc.M407715200

Nambi, S., Long, J. E., Mishra, B. B., Baker, R., Murphy, K. C., Olive, A. J., et al. (2015). The oxidative stress network of Mycobacterium tuberculosis reveals coordination between radical detoxification systems. Cell Host Microbe 17, 829-837. doi: 10.1016/j.chom.2015.05.008
Nandakumar, M., Nathan, C., and Rhee, K. Y. (2014). Isocitrate lyase mediates broad antibiotic tolerance in Mycobacterium tuberculosis. Nat. Commun. 5, $1-10$.

Nathan, C., and Shiloh, M. U. (2000). Reactive oxygen and nitrogen intermediates in the relationship between mammalian host and microbial pathogens. Proc. Natl. Acad. Sci. U.S.A. 97, 8841-8848. doi: 10.1073/pnas.97.16.8841

Nicolopoulou-Stamati, P., Hens, L., Howard, V. C., and Van Larebeke, N. (2004). Cancer as an Environmental Disease. New York, NY: Springer Science.

Nishiyama, Y., Massey, V., Takeda, K., Kawasaki, S., Sato, J., Watanabe, T., et al. (2001). Hydrogen peroxide-forming NADH oxidase belonging to the peroxiredoxin oxidoreductase family: existence and physiological role in bacteria. J. Bacteriol. 183, 2431-2438. doi: 10.1128/JB.183.8.2431-2438.2001

Oberley-Deegan, R. E., Rebits, B. W., Weaver, M. R., Tollefson, A. K., Bai, X., McGibney, M., et al. (2010). An oxidative environment promotes growth of Mycobacterium abscessus. Free Radic. Biol. Med. 49, 1666-1673. doi: 10.1016/ j.freeradbiomed.2010.08.026

Parrish, N. M., Ko, C. G., Hughes, M. A., Townsend, C. A., and Dick, J. D. (2004). Effect of n-octanesulphonylacetamide (OSA) on ATP and protein expression in Mycobacterium bovis BCG. J. Antimicrob. Chemother. 54, 722-729. doi: $10.1093 / \mathrm{jac} / \mathrm{dkh} 408$

Paulsen, C. E., and Carroll, K. S. (2010). Orchestrating redox signaling networks through regulatory cysteine switches. ACS Chem. Biol. 5, 47-62. doi: 10.1021/ cb900258z

Piskernik, C., Haindl, S., Behling, T., Gerald, Z., Kehrer, I., and Redl, H. (2008). Antimycin A and lipopolysaccharides cause the leakage of superoxide radicals from rat liver mitochondria. Biochim. Biophys. Acta 1782, 280-285. doi: 10. 1016/j.bbadis.2008.01.007

Reddy, M. K., Gupta, S. K., Jacob, M. R., Khan, S. I., and Ferreira, D. (2007). Antioxidant, antimalarial and antimicrobial activities of tannin-rich fractions, ellagitannins and phenolic acids from Punica granatum L. Planta Med. 73, 461-467. doi: 10.1055/s-2007-967167

Reusch, V. M., and Burger, M. M. (1974). Distribution of marker enzymes between mesosomal and protoplast membranes. J. Biol. Chem. 249, 5337-5345.

Rohde, K. H., Abramovitch, R. B., and Russell, D. G. (2007). Mycobacterium tuberculosis invasion of macrophages: linking bacterial gene expression to environmental cues. Cell Host Microbe 2, 352-364. doi: 10.1016/j.chom.2007. 09.006

Rottenberg, H., Covian, R., and Trumpower, B. L. (2009). Membrane potential greatly enhances superoxide generation by the cytochrome bcl complex reconstituted into phospholipid vesicles. J. Biol. Chem. 284, 19203-19210. doi: 10.1074/jbc.M109.017376

Russell, D. G. (2001). Mycobacterium tuberculosis: here today, and here tomorrow. Nat. Rev. Mol. Cell Biol. 2, 1-9. doi: 10.1038/35085034

Saran, M. (2003). To what end does nature produce superoxide? NADPH oxidase as an autocrine modifier of membrane phospholipids generating paracrine lipid messengers. Free Radic. Res. 37, 1045-1059.

Schnappinger, D., Ehrt, S., Voskuil, M. I., Liu, Y., Mangan, J. A., Monahan, I. M., et al. (2003). Transcriptional adaptation of Mycobacterium tuberculosis within macrophages: insights into the phagosomal. environment. J. Exp. Med. 19, 693-704. doi: 10.1084/jem.20030846

Shi, L., Sohaskey, C. D., North, R. J., and Gennaro, M. L. (2008). Transcriptional characterization of the antioxidant response of Mycobacterium tuberculosis in vivo and during adaptation to hypoxia in vitro. Tuberculosis (Edinb.) 88, 1-6. doi: 10.1016/j.tube.2007.08.007

Suresh, R. D., Annam, V., Pratibha, K., and Hamsaveena. (2010). Immunological correlation of oxidative stress markers in tuberculosis patients. Int. J. Biol. Med. Res. 1, 185-187.

Taneja, N. K., Dhingra, S., Mittal, A., Naresh, M., and Tyagi, J. S. (2010). Mycobacterium tuberculosis transcriptional adaptation, growth arrest and dormancy phenotype development is triggered by vitamin C. PLOS ONE 5:e10860. doi: 10.1371/journal.pone.0010860

Turrens, J. F. (2003). Mitochondrial formation of reactive oxygen species. J. Physiol. 552, 335-344. doi: 10.1113/jphysiol.2003.049478

Tyagi, P., Dharmaraja, A. T., Bhaskar, A., Chakrapani, H., and Singh, A. (2015). Mycobacterium tuberculosis has diminished capacity to counteract redox stress induced by elevated levels of endogenous superoxide. Free Radic. Biol. Med. 84, 344-354. doi: 10.1016/j.freeradbiomed.2015.03.008 
Verkaart, S., Koopman, W. J., van Emst-de Vries, S. E., Nijtmans, L. G., van den Heuvel, L. W., Smeitink, J. A., et al. (2007). Superoxide production is inversely related to complex I activity in inherited complex I deficiency. Biochim. Biophys. Acta 1772, 373-381. doi: 10.1016/j.bbadis.2006.12.009

Wayne, L. G., and Hayes, L. G. (1996). An in vitro model for sequential study of shift down of Mycobacterium tuberculosis through two stages of non-replicating persistence. Infect. Immun. 64, 2062-2069.

White, G. E., McNeill, E., Channon, K. M., and Greaves, D. R. (2014). Fractalkine promotes human monocyte survival via a reduction in oxidative stress. Arterioscler. Thromb. Vasc. Biol. 34, 2554-2562. doi: 10.1161/ATVBAHA.114. 304717

Wilcox, C. S., and Pearlman, A. (2008). Chemistry and antihypertensive effects of tempol and other nitroxides. Pharmacol. Rev. 60, 418-469. doi: 10.1124/pr.108. 000240

Yang, X., and Ma, K. (2007). Characterization of an exceedingly active $\mathrm{NADH}$ oxidase from the anaerobic hyperthermophilic bacterium Thermotoga maritime. J. Bacteriol. 189, 3312-3317. doi: 10.1128/JB. 01525-06

Zalba, G., Beaumont, F. J., San José, G., Fortuño, A., Fortuño, M. A., Etayo, J. C., et al. (2000). Vascular NADH/NADPH oxidase is involved in enhanced superoxide production in spontaneously hypertensive rats. Hypertension 35, 1055-1061. doi: 10.1161/01.HYP.35.5.1055

Zielonka, J., Hardy, M., and Kalyanaraman, B. (2009). HPLC study of oxidation products of hydroethidine in chemical and biological systems: ramifications in superoxide measurements. Free Radic. Biol. Med. 46, 329-338. doi: 10.1016/j. freeradbiomed.2008.10.031

Zielonka, J., Vasquez-Vivar, J., and Kalyanaraman, B. (2008). Detection of 2hydroxyethidium in cellular systems: a unique marker product of superoxide and hydroethidine. Nat. Prot. 3, 8-21. doi: 10.1038/nprot.2007.473

Conflict of Interest Statement: The authors declare that the research was conducted in the absence of any commercial or financial relationships that could be construed as a potential conflict of interest.

Copyright (C) 2017 Yeware, Shurpali, Athalye and Sarkar. This is an open-access article distributed under the terms of the Creative Commons Attribution License (CC BY). The use, distribution or reproduction in other forums is permitted, provided the original author(s) or licensor are credited and that the original publication in this journal is cited, in accordance with accepted academic practice. No use, distribution or reproduction is permitted which does not comply with these terms. 